\title{
Automotive Emission Control Catalysts
}

\author{
Jae-Soon Choi ${ }^{1}$ and Petr Kočí ${ }^{2}$ \\ 1 Fuels, Engines, and Emissions Research Center, Oak Ridge National Laboratory, Oak Ridge, TN 37831, USA; \\ choijs@ornl.gov \\ 2 Department of Chemical Engineering, University of Chemistry and Technology, Prague, Technicka 5, \\ CZ Prague 166 28, Czech Republic; petr.koci@vscht.cz
}

Academic Editor: Keith Hohn

Received: 14 September 2016; Accepted: 22 September 2016; Published: 6 October 2016

\section{Background}

Emission control catalysts constitute an essential part of today's vehicles powered by internal combustion engines, mitigating the harmful effects of pollutants in the exhaust such as carbon monoxide, hydrocarbons, nitrogen oxides, and particulate matter [1]. Impressive technical advances have been made since the introduction of the first catalytic converters in the 1970s for the abatement of carbon monoxide and hydrocarbon emissions from gasoline vehicles. In many countries today, exhaust gases from both gasoline and diesel engines are extensively cleaned up using a suite of advanced catalyst technologies, including: three-way catalyst (TWC), diesel particulate filter (DPF), diesel oxidation catalyst (DOC), selective catalytic reduction (SCR), and $\mathrm{NO}_{x}$ storage and reduction (NSR) catalysts.

Despite this success, significant research and development activities are under way in industry and academia to further enhance the performance of existing catalysts and to develop novel technologies (e.g., passive $\mathrm{NO}_{x}$ adsorbers, SCR on DPF and TWC on gasoline particulate filters). Much of the current efforts aim at helping address three major challenges facing the automotive industry $[2,3]$. First, the emission regulations around the world have become increasingly more stringent requiring continued catalyst activity, durability and selectivity improvements (e.g., reduced formation of byproducts such as $\mathrm{N}_{2} \mathrm{O}$, a potent greenhouse gas). Moreover, driven by the public concern regarding energy security and climate change, the efficiency of internal combustion engines is improving at a rapid pace. This efficiency gain entails a significant decrease in the exhaust temperature due to reduced waste heat generation. To successfully meet this so-called low-temperature challenge-to achieve over $90 \%$ conversion at $150{ }^{\circ} \mathrm{C}$ or lower without compromising emission control cost—innovative catalyst solutions and operating strategies need to be developed (e.g., new catalyst formulations and systems conducive to light-off temperatures below $150^{\circ} \mathrm{C}$ ) [4]. Finally, greater use of alternative fuels such as natural gas and biofuels presents the third major challenge in catalyst development, considering, for instance, specific reactivity of unburned methane from natural gas engines or biomass-derived fuel impurities impacting catalyst durability.

\section{This Special Issue}

Some of the leading experts contributed to this Special Issue of Catalysts reporting on recent advances made by their teams on various catalyst technologies relevant to future automotive emission control development including TWC, urea-SCR, $\mathrm{NH}_{3}-\mathrm{SCR}, \mathrm{CH}_{4}-\mathrm{SCR}, \mathrm{NSRC}$, and DOC.

After giving a mini-review on modern three-way catalysts and systems in an Introduction, Zheng et al. describe fuel shutoff (an engine operating strategy practiced to enhance fuel economy) and resultant catalyst temperature increase leading to catalyst deactivation, specifically related to $\mathrm{Rh}$ which is a main TWC catalyst component responsible for NO reduction [5]. The authors' simulated bench reactor evaluation and catalyst characterization shows that $\mathrm{Rh}$ supported on $\mathrm{Ce}_{x} \mathrm{O}_{y}-\mathrm{ZrO}_{2}$ is 
less deactivated by fuel shutoff (i.e., oxidative thermal aging) and its regeneration via fuel-rich engine operation is faster than $\mathrm{Rh}$ on $\mathrm{Al}_{2} \mathrm{O}_{3}$. Stronger metal-support interaction between $\mathrm{Rh}$ and $\mathrm{Al}_{2} \mathrm{O}_{3}$ leads to stable rhodium aluminate complex. Hydrogen generated in situ via steam reforming of fuel hydrocarbons over reduced $\mathrm{Rh}$ is believed to facilitate catalyst regeneration during the slightly fuel-rich operation.

In a companion paper [6], Zheng et al. investigate Pd (another major TWC component generally responsible for oxidation reactions) in the context of fuel shutoff influence and possibilities of rich regeneration. In contrast to $\mathrm{Rh}, \mathrm{Pd}$ deactivation is mainly due to $\mathrm{Pd}$ metal sintering resulting in irreversible deactivation for both $\mathrm{Pd} / \mathrm{Al}_{2} \mathrm{O}_{3}$ and $\mathrm{Pd} / \mathrm{Ce}_{x} \mathrm{O}_{y}-\mathrm{ZrO}_{2}$ catalysts. Fuel-rich operation and accompanying in situ $\mathrm{H}_{2}$ generation via steam reforming is not effective in recovering catalyst activity. The authors point out that stabilizing $\mathrm{PdO}$ (active state of $\mathrm{Pd}$ ) against decomposition into Pd would represent a breakthrough for TWC technology.

The paper co-authored by Xie et al. [7] aims to reveal the impact of phosphate-based lubricant additives on the aging and performance of commercial three-way catalyst (TWC) commonly used in passenger cars with stoichiometric gasoline engines. The $\mathrm{CO}, \mathrm{C}_{3} \mathrm{H}_{6}$ and NO light-off temperatures after catalyst aging are compared for the engine operation without any lubricant additive, and with two different additives. The TWCs that converted exhaust gas from the engines operated with lubricant additives exhibit generally higher light-off temperature; however, the actual extent of catalyst deactivation depends on the nature of the additive. The variations are correlated with the build-up of different forms of phosphates within the catalyst support material when using different lubricant additives. The formation of aluminum phosphate is identified as less detrimental for TWC function than that of cerium phosphate.

While $\mathrm{NH}_{3}$-SCR catalysts are highly effective in lean $\mathrm{NO}_{x}$ control, due to safety reasons, $\mathrm{NH}_{3}$ reductant needs to be generated from liquid urea-water solution stored on-board in a special tank and injected into exhaust pipe in front of the catalyst. This arrangement, however, results in additional complexities in designing catalytic systems to ensure efficient urea decomposition and hydrolysis into $\mathrm{NH}_{3}$ molecules. Based on the results obtained from well-controlled micro-scale reactor experiments, Seneque et al. describe potential limitations of urea as an $\mathrm{NH}_{3}$ carrier when urea residence time is not sufficient [8]. They further show that the observed lack of $\mathrm{NH}_{3}$ availability can be attributed to the insufficient SCR catalyst activity for isocyanic acid (HNCO: urea decomposition product) hydrolysis, which can be complemented by adding an active hydrolysis catalyst (e.g., $\mathrm{ZrO}_{2}$ ) upstream of the SCR catalyst.

Metal supported vanadia is an important $\mathrm{NH}_{3}-\mathrm{SCR}$ catalyst group available for diesel applications, and its performance is highly dependent on $\mathrm{V}$ loading. The paper by Marberger et al. [9] further clarifies the relationship between $\mathrm{V}$ loading and activity and selectivity, thus providing useful information for optimization of catalyst formulation and performance. An ideal $\mathrm{V}_{2} \mathrm{O}_{5}$ loading is found between 2.0 and $2.6 \mathrm{wt}$. \%; the activity of $\mathrm{V}_{2} \mathrm{O}_{5} / \mathrm{WO}_{3}-\mathrm{TiO}_{2}$ is insufficient below $2.0 \mathrm{wt}$. \%, while hydrothermal aging induced deactivation occurs above $2.6 \mathrm{wt}$. \%. The loading and surface coverage of $\mathrm{WO}_{x}$ promoter is also an important parameter to control.

$\mathrm{NO}_{x}$ storage and reduction catalyst also known as lean $\mathrm{NO}_{x}$ trap (LNT) represents an exhaust gas aftertreatment technology used for abatement of nitrogen oxides from diesel and lean-burn gasoline engines. The catalyst is operated in periodical regime alternating between lean and rich phases. During the lean phase, $\mathrm{NO}_{x}$ adsorption takes place in excess of oxygen. Reduction of the accumulated $\mathrm{NO}_{x}$ is then achieved within the rich phase, characterized by increased concentration of $\mathrm{CO}$, hydrogen and hydrocarbons formed by injecting extra fuel for a short duration. Kubiak et al. investigate reaction pathways during the reduction of the adsorbed $\mathrm{NO}_{x}$ [10]. They focus on the effect of precious metal in the catalyst formulation ( $\mathrm{Pt}$ or $\mathrm{Rh}$ ), taking into account the range of operating temperature and different forms of adsorbed $\mathrm{NO}_{x}$ species (nitrites or nitrates). The differences in $\mathrm{NO}_{x}$ conversions and selectivities to $\mathrm{N}_{2}, \mathrm{~N}_{2} \mathrm{O}$ and $\mathrm{NH}_{3}$ are attributed to different oxidation activity, reducibility and dispersion of $\mathrm{Pt}$ and $\mathrm{Rh}$ in the examined catalysts. 
Nowadays, the engines powered by natural gas gain increasing popularity in the automotive industry and their share on the market increases particularly in the segment of commercial vehicles where fuel economy is of high interest. The contribution from Mendes et al. systematically examines the role of $\mathrm{Pd}$ and Ce in Pd-MOR and PdCe-MOR zeolite catalysts for selective catalytic reduction of nitrogen oxides by methane under excess of oxygen [11]. The $\mathrm{CH}_{4}$ and $\mathrm{NO}_{x}$ conversions and selectivities are measured for several different catalyst configurations, including the effects of $\mathrm{Pd}$ loading, impregnation method (incipient wetness or ion exchange at different temperatures), and the order of $\mathrm{Pd}$ and Ce component addition. This work underlines the importance of introducing $\mathrm{Pd}$ to zeolite via ion exchange and before $\mathrm{Ce}$ addition to achieve high $\mathrm{CH}_{4}-\mathrm{SCR}$ activity.

$\mathrm{NO}$ oxidation to $\mathrm{NO}_{2}$ in DOC affects the performance of other catalyst types found in diesel exhaust gas aftertreatment systems. $\mathrm{NO}_{2}$ represents a more reactive form of nitrogen oxides and it can be utilized for soot oxidation in particulate filters, to accelerate $\mathrm{NO}_{x}$ adsorption in LNT or to achieve higher conversions in SCR. The team of Mihai, Creaser and Olsson presents a fundamental investigation of $\mathrm{NO}$, oxygen and $\mathrm{NO}_{2}$ adsorption, desorption and reaction steps over $\mathrm{Pt} / \mathrm{Al}_{2} \mathrm{O}_{3}$ catalyst, using microcalorimetric study to evaluate the adsorption enthalpies [12]. While the heat of $\mathrm{NO}$ adsorption is practically constant, the oxygen adsorption enthalpy varies with oxygen coverage and it is further influenced by platinum oxide formation, which affects also the NO oxidation rate.

We gratefully acknowledge the contributing authors for sharing their recent work in this Special Issue and the peer reviewers for providing critical feedback and useful suggestions. We also thank Prof. Keith Hohn, Editor-in-Chief for inviting us as guest editors, and Ms. Mary Fan and the Catalyst Editorial Office staff for the great help and excellent partnership. Our work was supported by the U.S. Department of Energy Vehicle Technologies Office under contract number DE-AC05-00OR22725 and the Czech Ministry of Education (Project LH 12086).

NOTICE OF COPYRIGHT: This manuscript has been authored by UT-Battelle, LLC under Contract No. DE-AC05-00OR22725 with the U.S. Department of Energy. The United States Government retains and the publisher, by accepting the article for publication, acknowledges that the United States Government retains a non-exclusive, paid-up, irrevocable, worldwide license to publish or reproduce the published form of this manuscript, or allow others to do so, for United States Government purposes. The Department of Energy will provide public access to these results of federally sponsored research in accordance with the DOE Public Access Plan (http:/ / energy.gov/downloads/doe-public-access-plan).

Conflicts of Interest: The authors declare no conflict of interest.

\section{References}

1. Heck, R.M.; Farrauto, R.J.; Gulati, S.T. Catalytic Air Pollution Control: Commercial Technology, 3rd ed.; John Wiley \& Sons, Inc.: Hoboken, NJ, USA, 2009.

2. Johnson, T. Vehicular Emissions in Review. SAE Int. J. Engines 2016, 9, 1258-1275. [CrossRef]

3. Pihl, J.A.; Blint, R.; Daw, C.S. 2015 CLEERS Industry Priorities Survey Final Report. Available online: http://cleers.org/reports/2015_CLEERS_Industry_Priorities\%20Survey_Final_Report.pdf (accessed on 31 August 2016).

4. Zammit, M.; DiMaggio, C.; Kim, C.; Lambert, C.; Muntean, G.; Peden, C.; Parks, J.; Howden, K. Future Automotive Aftertreatment Solutions: The $150{ }^{\circ} \mathrm{C}$ Challenge Workshop Report. Available online: http://cleers.org/acec-lowt/includes/The_150C_Challenge_Workshop_Report.pdf (accessed on 31 August 2016).

5. Zheng, Q.; Farrauto, R.; Deeba, M.; Valsamakis, I. Part I: A Comparative Thermal Aging Study on the Regenerability of $\mathrm{Rh} / \mathrm{Al}_{2} \mathrm{O}_{3}$ and $\mathrm{Rh} / \mathrm{Ce}_{x} \mathrm{O}_{y}-\mathrm{ZrO}_{2}$ as Model Catalysts for Automotive Three Way Catalysts. Catalysts 2015, 5, 1770-1796. [CrossRef]

6. Zheng, Q.; Farrauto, R.; Deeba, M. Part II: Oxidative Thermal Aging of Pd/ $\mathrm{Al}_{2} \mathrm{O}_{3}$ and $\mathrm{Pd} / \mathrm{Ce}_{x} \mathrm{O}_{y}-\mathrm{ZrO}_{2}$ in Automotive Three Way Catalysts: The Effects of Fuel Shutoff and Attempted Fuel Rich Regeneration. Catalysts 2015, 5, 1797-1814. [CrossRef] 
7. Xie, C.; Toops, T.J.; Lance, M.J.; Qu, J.; Viola, M.B.; Lewis, S.A.; Leonard, D.N.; Hagaman, E.W. Impact of Lubricant Additives on the Physicochemical Properties and Activity of Three-Way Catalysts. Catalysts 2016, 6, 54. [CrossRef]

8. Seneque, M.; Can, F.; Duprez, D.; Courtois, X. Use of a $\mu$-Scale Synthetic Gas Bench for Direct Comparison of Urea-SCR and $\mathrm{NH}_{3}$-SCR Reactions over an Oxide Based Powdered Catalyst. Catalysts 2015, 5, 1535-1553. [CrossRef]

9. Marberger, A.; Elsener, M.; Ferri, D.; Kröcher, O. $\mathrm{VO}_{x}$ Surface Coverage Optimization of $\mathrm{V}_{2} \mathrm{O}_{5} / \mathrm{WO}_{3}-\mathrm{TiO}_{2}$ SCR Catalysts by Variation of the V Loading and by Aging. Catalysts 2015, 5, 1704-1720. [CrossRef]

10. Kubiak, L.; Castoldi, L.; Lietti, L.; Andonova, S.; Olsson, L. Mechanistic Investigation of the Reduction of $\mathrm{NO}_{x}$ over Pt- and Rh-Based LNT Catalysts. Catalysts 2016, 6, 46. [CrossRef]

11. Mendes, A.N.; Ribeiro, M.F.; Henriques, C.; Da Costa, P. On the Effect of Preparation Methods of PdCe-MOR Catalysts as $\mathrm{NO}_{x} \mathrm{CH}_{4}$-SCR System for Natural Gas Vehicles Application. Catalysts 2015, 5, 1815-1830. [CrossRef]

12. Mihai, O.; Creaser, D.; Olsson, L. Adsorption and Oxidation Investigations over $\mathrm{Pt} / \mathrm{Al}_{2} \mathrm{O}_{3}$ Catalyst: A Microcalorimetric Study. Catalysts 2016, 6, 73. [CrossRef]

(C) 2016 by the authors; licensee MDPI, Basel, Switzerland. This article is an open access article distributed under the terms and conditions of the Creative Commons Attribution (CC-BY) license (http://creativecommons.org/licenses/by/4.0/). 